Article

\title{
Crack-Assisted Charge Injection into Solvent-Free Liquid Organic Semiconductors via Local Electric Field Enhancement
}

\author{
Kyoung-Hwan Kim ${ }^{1}$, Myung-June Park ${ }^{1,2}$ a and Ju-Hyung Kim ${ }^{1,2, *(D)}$ \\ 1 Department of Energy Systems Research, Ajou University, Suwon 16499, Korea; \\ kkh0217@ajou.ac.kr (K.-H.K.); mjpark@ajou.ac.kr (M.-J.P.) \\ 2 Department of Chemical Engineering, Ajou University, Suwon 16499, Korea \\ * Correspondence: juhyungkim@ajou.ac.kr
}

Received: 26 June 2020; Accepted: 27 July 2020; Published: 28 July 2020

\begin{abstract}
Non-volatile liquid organic semiconducting materials have received much attention as emerging functional materials for organic electronic and optoelectronic devices due to their remarkable advantages. However, charge injection and transport processes are significantly impeded at interfaces between electrodes and liquid organic semiconductors, resulting in overall lower performance compared to conventional solid-state electronic devices. Here we successfully demonstrate efficient charge injection into solvent-free liquid organic semiconductors via cracked metal structures with a large number of edges leading to local electric field enhancement. For this work, thin metal films on deformable polymer substrates were mechanically stretched to generate cracks on the metal surfaces in a controlled manner, and charge injection properties into a typical non-volatile liquid organic semiconducting material, (9-2-ethylhexyl)carbazole (EHCz), were investigated in low bias region (i.e., ohmic current region). It was found that the cracked structures significantly increased the current density at a fixed external bias voltage via the local electric field enhancement, which was strongly supported by field intensity calculation using COMSOL Multiphysics software. We anticipate that these results will significantly contribute to the development and further refinement of various organic electronic and optoelectronic devices based on non-volatile liquid organic semiconducting materials.
\end{abstract}

Keywords: organic electronics; liquid semiconductors; charge injection; surface engineering; crack engineering

\section{Introduction}

Non-volatile liquid organic semiconducting materials have attracted a lot of interest as emerging functional materials for organic electronic and optoelectronic devices in recent years, because these fluidic materials present outstanding advantages such as tunable optoelectronic responses, degradation-free characteristics, solvent-free processability, and ultimate mechanical flexibility and uniformity [1-8]. Various electronic and optoelectronic applications, such as photorefractive devices, organic light-emitting diodes, dye-sensitized solar cells, memory devices, and optically pumped lasers, have been already demonstrated using non-volatile liquid organic semiconductors as active materials [5-16]. In particular, it has been reported that fresh liquid organic semiconductors can be continuously injected into the devices through microfluidic channels for preventing performance degradation $[15,16]$. However, due to the relatively low efficiency in comparison with conventional solid-state devices, considerable research efforts have been devoted to the development of novel molecular structures and device architectures to improve device performance, which is still a challenge $[1,11,13-17]$. 
Since charge carriers (i.e., electrons and holes) for operating organic electronic and optoelectronic devices should be essentially injected from electrodes, efficient charge injection into the liquid organic layers is necessarily required to realize high-performance devices based on the non-volatile liquid organic semiconductors $[3,17,18]$. However, the fluidity of the liquid organic materials causes difficulties in inducing preferable molecular orientations on the electrodes for facilitating charge injection, and intermolecular distances in liquid phases are intrinsically longer than those in solid phases (i.e., less dense molecular packing in liquid phases). Charge injection and transport processes are thus significantly impeded at the interfaces between the electrodes and the liquid organic materials, resulting in overall lower performance [19-25]. In this context, various methods such as inserting buffer layers and adding ionic dopants have been employed to reduce charge injection barriers and to increase charge carrier concentrations [12,26-32]. In addition, the charge carrier injection into the organic liquid materials is expected to be significantly improved if the local electric fields inducing the migration of charge carriers near the interfaces are enhanced $[18,26,27,33,34]$. The electric fields are spontaneously concentrated at the edges of the field plates (i.e., edge effect) [35-38], where the field intensities are locally increased, and thus the field plate structures (i.e., shapes of electrodes) play a decisive role in the spatial distributions of electric fields. This phenomenon is also applicable to interface engineering for improving the charge injection characteristics of organic electronic devices.

Here we successfully demonstrate efficient charge injection into solvent-free liquid organic semiconductors via cracked metal structures with a large number of edges leading to local electric field enhancement. For this work, silver (Ag) thin films, deposited on deformable fluorinated ethylene propylene (FEP) substrates, were used to generate cracks on the field plates in a controlled manner. The Ag films on the polymer substrates were mechanically gripped and stretched up to fixed ratios, resulting in the formation of the cracks with reproducible patterns $[39,40]$. Although this simple cracking method can be easily performed to fabricate a large number of edges on metal surfaces without any lithographic processes, heavily cracked metal electrodes normally give a rise to high electrical resistance resulting in performance degradation [41-43]. To avoid increases in electrical resistance originating from the structural deformations, the cracked Ag films were transferred and welded onto other intact Ag films to complete the electrode structures, and then the charge injection properties were investigated using a typical non-volatile liquid organic semiconducting material, (9-2-ethylhexyl)carbazole (EHCz) [1,5-8,10,12-14]. The fluidity of EHCz with a glass transition temperature below $0{ }^{\circ} \mathrm{C}$ facilitates the penetration of the molecules into the crack structures of the electrodes, clearly showing the effects of the engineered interfacial structures in charge injection. It was found that the cracked structures significantly increased the current density at a fixed external bias voltage via the local electric field enhancement, which was strongly supported by field intensity calculation using COMSOL Multiphysics software. These results suggest great potential for the development and further refinement of various organic electronic and optoelectronic devices based on non-volatile liquid organic semiconducting materials.

\section{Materials and Methods}

\subsection{Materials}

The deformable FEP films with a thickness of $0.125 \mathrm{~mm}$ (Teflon®FEP) and EHCz were purchased from Alphaflon (Seoul, Korea) and Sigma Aldrich (Seoul, Korea), respectively, and used as received.

\subsection{Device Fabrication}

The cracked metal electrodes used in this work were prepared as schematically illustrated in Figure 1. The Ag thin films with a thickness of $30 \mathrm{~nm}$ were preferentially deposited on the deformable FEP substrates by thermal evaporation in vacuum $\left(<1.0 \times 10^{-6}\right.$ Torr $)$. The samples were individually gripped in a rectangular frame for applying tensile forces, and then uniaxially and biaxially stretched to $120 \%$ and $140 \%$, respectively (designated "UA120", "UA140", "BA120", and "BA140"; see also 
Table 1). It should be noted that the maximum stretching ratio which was reliable without tearing or slipping of the sample in our experimental setup was $140 \%$. To prevent an increase in electrical resistance, each cracked Ag film was transferred and welded onto another intact Ag film by means of cold-welding [44-47]. For the cold-welding process, the stretched Ag/FEP sample was brought into contact with the intact Ag film (with a 30-nm thickness) deposited on a glass substrate, and subsequently pressed with a pressure of $0.2 \mathrm{MPa}$ for $90 \mathrm{~s}$ at room temperature. The FEP substrate was then easily peeled off from the sample without residue owing to a lower surface energy of FEP (see Figure 1c). All the transferred samples exhibited no significant change in high electrical conductivity, compared to a reference electrode (i.e., the intact Ag film with a 60-nm thickness deposited on the glass substrate). It was also confirmed that the cracked Ag films were neatly transferred onto the intact Ag films, using scanning electron microscopy (SEM).

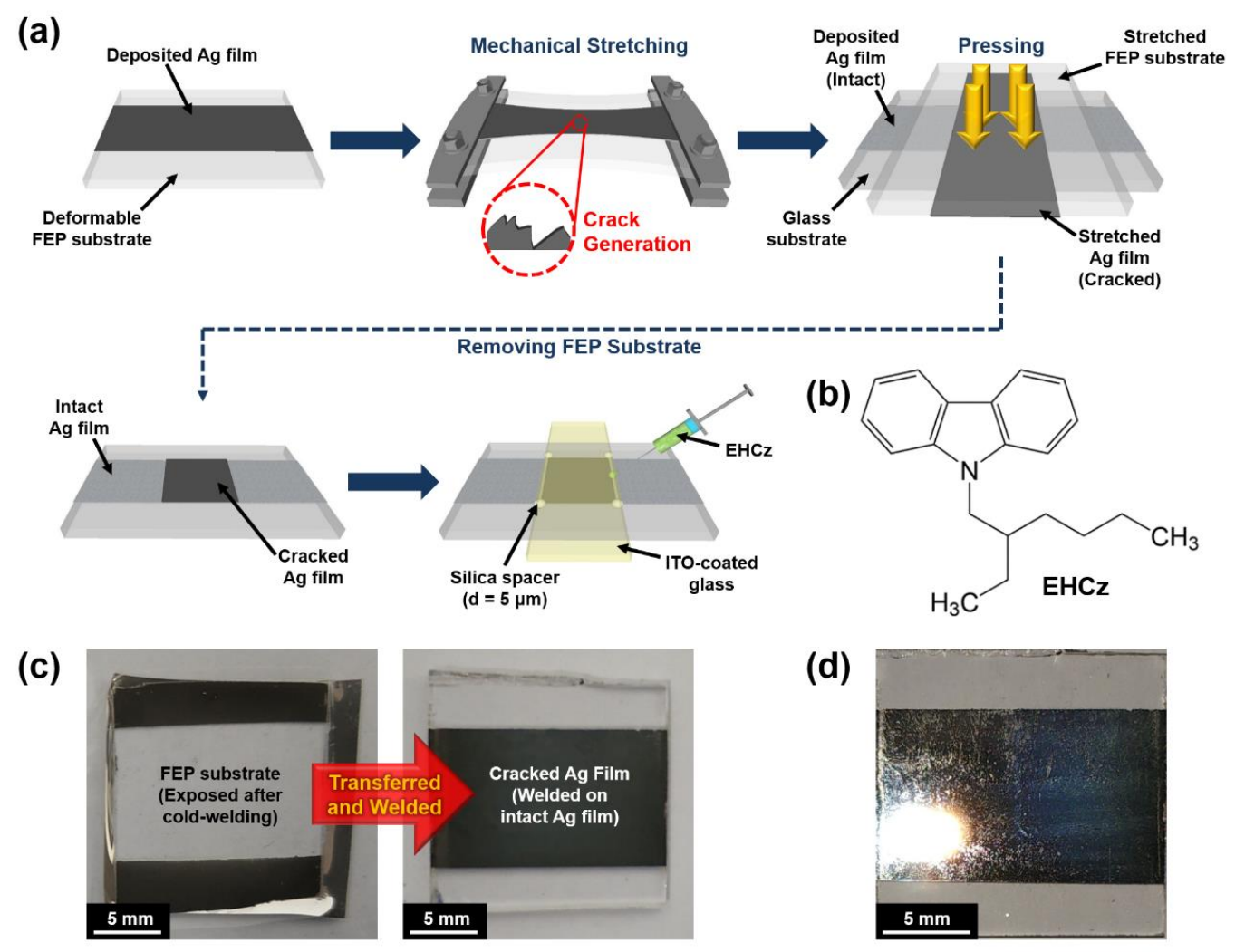

Figure 1. (a) Schematic illustration of the preparation of cracked Ag electrode in a controlled manner, and the fabrication of device. (b) Chemical structure of (9-2-ethylhexyl)carbazole (EHCz). (c) Photographic images of the cracked Ag film after completing the cold-welding process. (d) Photographic image of the cracked Ag film inducing diffuse reflection.

Table 1. Stretching ratios of Ag films.

\begin{tabular}{ccc}
\hline Sample Name & Stretching Ratio (X-Axis) & Stretching Ratio (Y-Axis) \\
\hline Reference & $0 \%$ & $0 \%$ \\
UA120 & $20 \%$ & $0 \%$ \\
UA140 & $40 \%$ & $0 \%$ \\
BA120 & $20 \%$ & $20 \%$ \\
BA140 & $40 \%$ & $40 \%$ \\
\hline
\end{tabular}

$\mathrm{X}$ - and Y-axes are in-plane, which are perpendicular to each other.

Each prepared Ag electrode was covered with another glass substrate coated with indium-tin oxide (ITO) $\left(20 \Omega \mathrm{sq}^{-1}\right)$, and silica microsphere spacers (of 5- $\mu \mathrm{m}$ diameter) were used for a fixed gap 
distance between Ag and ITO. The gap between the two electrodes was then filled with EHCz by capillary action to complete the device structure (see Figure 2). The active area of each device was $1 \times 1 \mathrm{~cm}^{2}$. It is worth noting that EHCz is highly viscous, which substantially hinders the infiltration into smaller gaps (in the submicron range). Even if EHCz well stays in the gap without leakage due to its high viscosity, the two substrates (i.e., lower and cover glasses) should be securely fixed to prevent slipping by the liquid.

(a)

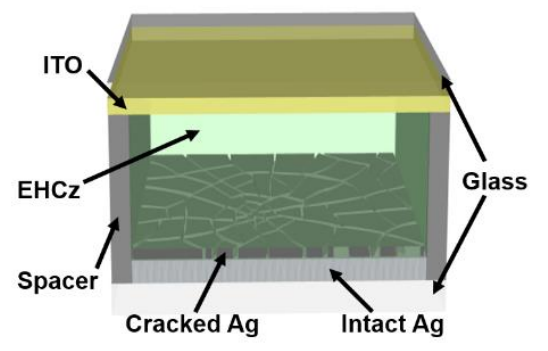

(b)

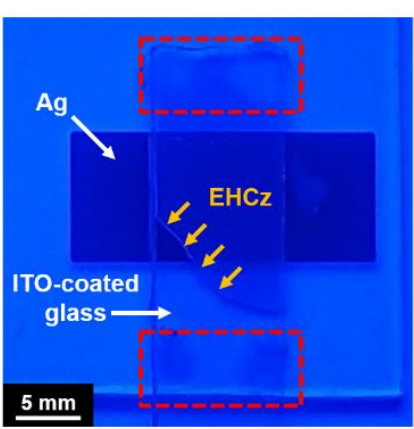

(c)

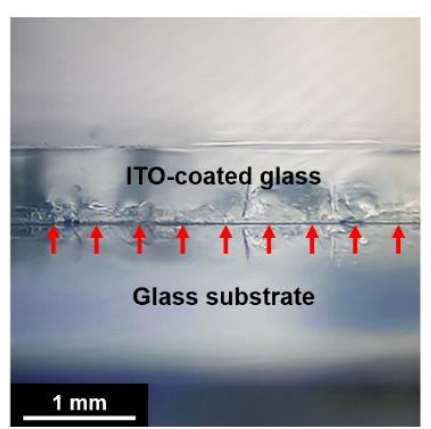

Figure 2. (a) Configuration of device to investigate the charge injection properties via local electric field enhancement. (b) Photographic image of the device illustrated in (a), under $365 \mathrm{~nm}$ UV light. The optically excited EHCz material under UV irradiation clearly revealed its liquid boundary during the capillary action (indicated by yellow arrows). Red dashed boxes indicate the locations of silica microsphere spacers. (c) Optical microscopy image of a cross section of the device in (b). The gap between the two electrodes is indicated by red arrows.

\subsection{Measurements}

The current density-voltage $(\mathrm{J}-\mathrm{V})$ characteristics of the devices were measured in response to a voltage sweep from 0.0 to $+1.0 \mathrm{~V}$, using a Keithley 2636 source meter. The capacitance of EHCz was also measured with Agilent 4284A Precision LCR Meter (Agilent, Santa Clara, CA, USA), to evaluate the dielectric constant.

\subsection{Field Intensity Calculation}

The field intensity within the device was calculated using COMSOL Multiphysics software (Burlington, MA, USA). Model structure of the device was prepared, based on the experimental observation as will be discussed in the Section 3. Static analysis was also performed to elucidate the spatial distribution of local electric fields within the device at a fixed bias voltage of $+1.0 \mathrm{~V}$.

\section{Results}

The prepared Ag electrodes via mechanical stretching exhibited a matt dark gray color, because the cracked metal structures cause diffuse reflections rather than specular reflections (see Figure 1d). To confirm the overall shapes of the cracks formed on the Ag electrodes, the samples after completing the cold-welding processes were investigated using SEM as shown in Figures 3 and 4. For the UA120 and UA140 samples (i.e., uniaxially stretched to $120 \%$ and $140 \%$, respectively), the Ag films tended to crack in the form of a one-dimensional line. With an increase in the uniaxial stretching ratio, the overall crack size increased, and the edges of the cracks were more clearly observed. Particularly, in the UA140 sample, minor cracks were further observed between the major cracks, leading to a higher crack density compared to UA120 (see Figure 3d). For the BA120 sample, which was biaxially stretched to $120 \%$, the orientations of the cracks were significantly diversified in comparison with the uniaxially stretched samples. The overall shape and density of the cracks were comparable to the minor cracks of UA140; however, large cracks similar to the major cracks of UA140 with the well-defined edges were not observed in BA120. As the biaxial stretching ratio increased up to 140\% (i.e., BA140), the Ag 
film was eventually divided into island forms by major cracks, and an average area of the islands was found to be less than $3 \mu \mathrm{m}^{2}$. In comparison with the other samples, minor cracks with a higher density were clearly observed within the Ag islands as shown in Figure $3 \mathrm{~h}$.

(a)

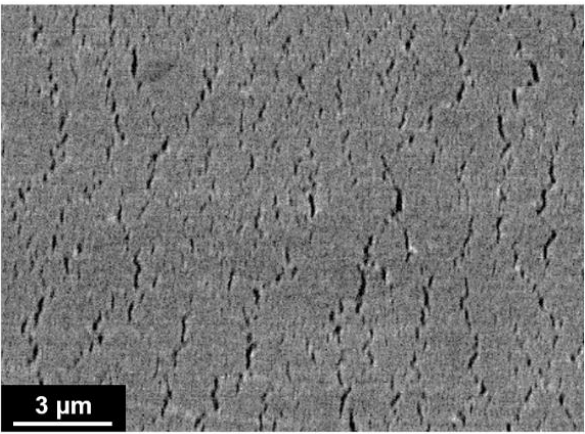

(c)

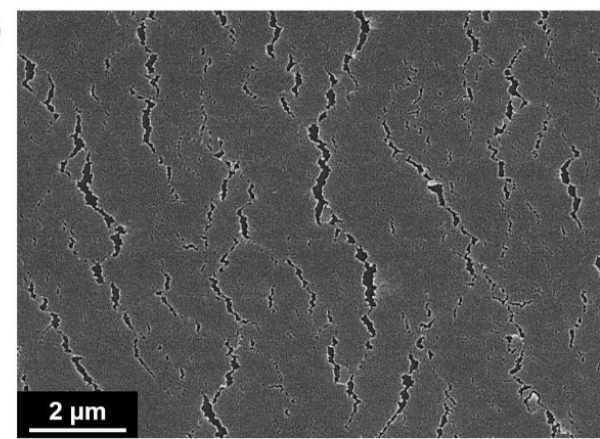

(e)

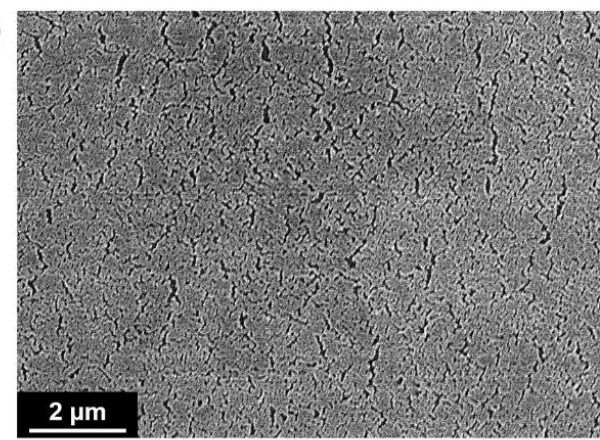

(g)

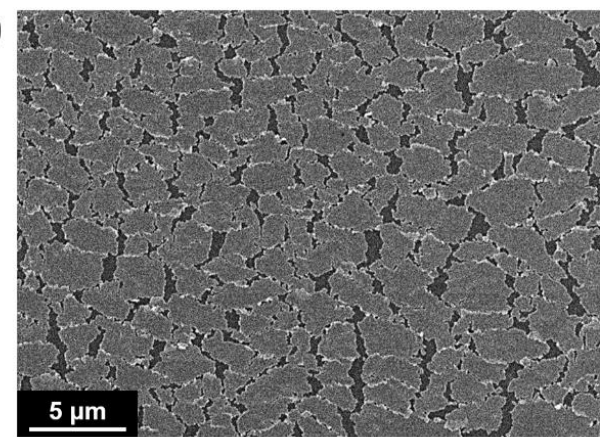

(b)

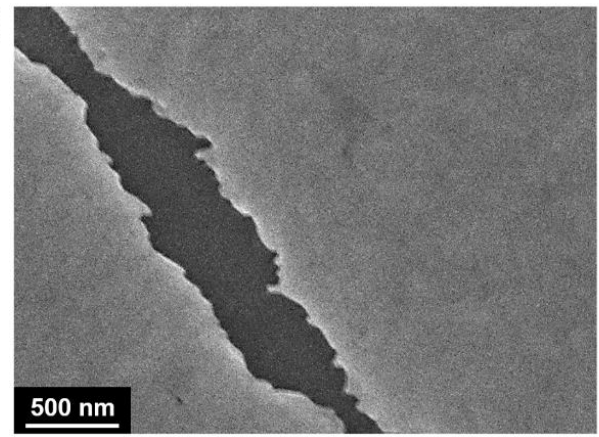

(d)

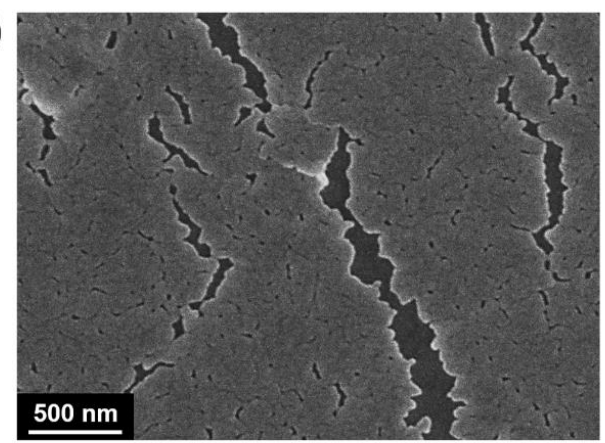

(f)

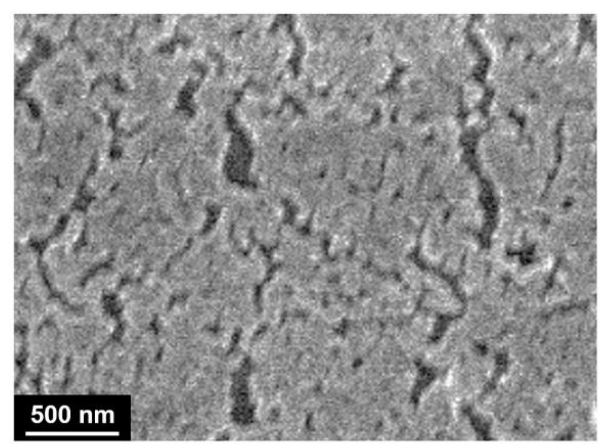

(h)

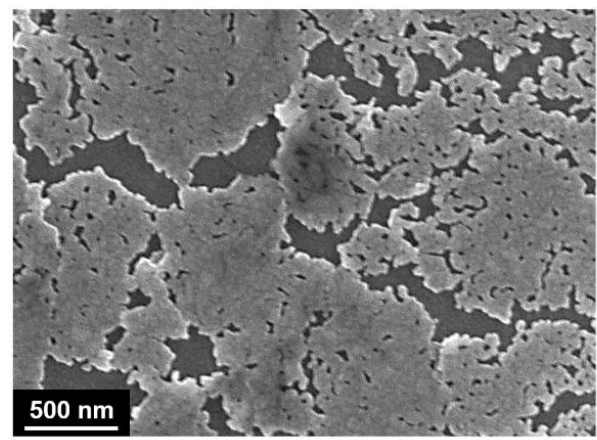

Figure 3. SEM images of the cracked Ag electrodes after completing the cold-welding processes. (a,b) SEM images of the UA120 sample. No further deformation of Ag was observed between crack lines as in (b). (c,d) SEM images of the UA140 samples. Minor cracks were further observed between major crack lines as in (d). (e,f) SEM images of the BA120 sample. Orientations of cracks were significantly diversified in comparison with the uniaxially stretched samples as in (f). (g,h) SEM images of the BA140 sample. The Ag film was divided into island forms as in (g), and minor cracks with a high density were clearly observed within the Ag islands as in (h). 
(a)

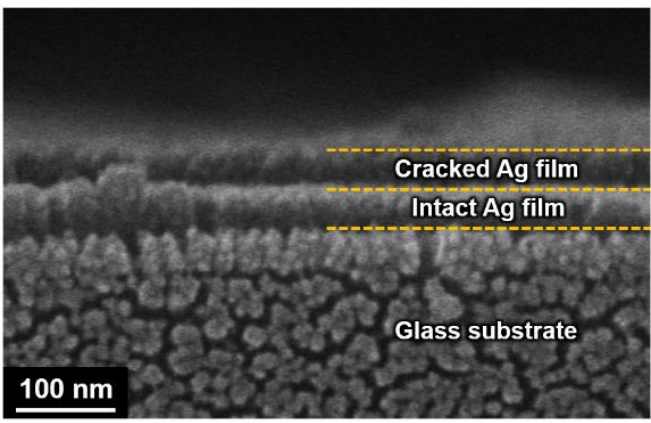

(b)

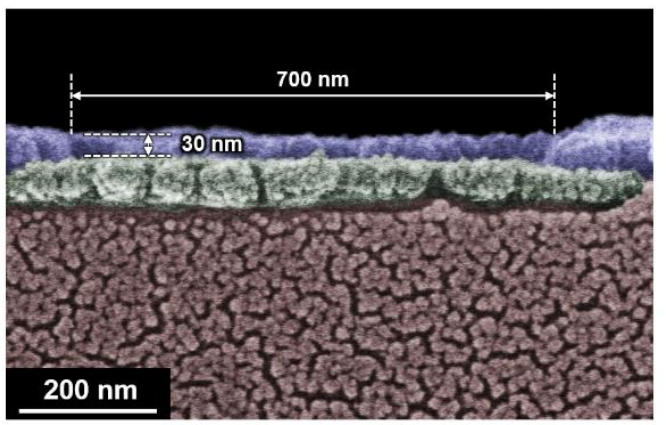

Figure 4. (a) SEM image of a selected cross section of the BA140 sample after completing the cold-welding process. (b) Colored SEM image of a selected cross section of the same sample as in (a). Red, green, and blue regions represent the glass substrate, the intact Ag film, and the cracked Ag film, respectively. The cross section of the crack (with $700 \mathrm{~nm}$ width and $30 \mathrm{~nm}$ depth) is clearly revealed in the blue region.

Figure 4 also shows cross-sectional SEM images of the BA140 sample. For these SEM measurements, platinum $(\mathrm{Pt}$ ) was coated onto the sample with a thickness of $\sim 5 \mathrm{~nm}$ to clearly observe the non-conductive glass substrate. It was confirmed that the cracked Ag film was neatly transferred and welded on the intact Ag film through the cold-welding process. It is worth noting here that metal oxide layers could not be easily transferred and welded onto other substrates in our experimental setup, and thus binding materials would be required to enhance adhesion.

The J-V characteristics for the devices were measured in response to a voltage sweep from 0.0 to $+1.0 \mathrm{~V}$, as shown in Figure 5. It should be noted that the charge carriers are normally accumulated in the organic layers in high bias voltage region, due to the relatively low charge carrier mobility. Such charge carrier accumulations in the organic layers give a rise to changes not only in the electric field distributions, but also in the J-V characteristics (i.e., from ohmic currents to space-charge-limited currents) $[17,26,28,48,49]$. Thus, changes in the charge injection properties according to the local electric field enhancement can be more clearly examined in low bias region (i.e., ohmic current region). As indicated in Figure 5, the current density was gradually increased as the density of the cracks on the Ag electrode increased. In particular, it was found that the slope ratio of the device with the BA140 electrode to the reference devices was $\sim 170$ in the J-V characteristics. At a fixed bias voltage of $+1.0 \mathrm{~V}$, the current densities were measured to be $6.68 \times 10^{-8}, 6.60 \times 10^{-7}, 1.08 \times 10^{-6}, 2.20 \times 10^{-6}$, and $1.16 \times 10^{-5} \mathrm{~A} \mathrm{~cm}^{-2}$ for reference, UA120, BA120, UA140, and BA140, respectively. It is worth noting that $\mathrm{EHCz}$ is an intrinsically p-type material, of which conduction is entirely governed by holes [1], and the devices presented in this work can be described as hole-only devices.

All the devices showed linear J-V characteristics within the bias voltage range (i.e., 0.0 to $+1.0 \mathrm{~V}$ ), indicating the ohmic behaviors of the devices in low bias region. If there is no change in charge carrier mobility, the ohmic currents of organic electronic devices at constant temperature are normally enhanced as the initial concentrations of charge carriers within the semiconducting layers increase using ionic dopants [31,32]. However, in this work, the increases in the ohmic currents were solely induced by the injected charges from the electrodes without using any extra dopants. These results strongly suggest that efficient charge injection via local electric field enhancement can exert similar effects to the introduction of ionic dopants on J-V characteristics in terms of charge carrier concentrations. It is notable that the maximum ohmic current density of $1.16 \times 10^{-5} \mathrm{~A} \mathrm{~cm}^{-2}$ in this work is relatively lower than those of other solid-state devices based on carbazole derivatives or similar organic semiconducting materials. In ITO/undoped organic semiconductor/metal structures, previous works reported ohmic current densities of $\sim 10^{-4} \mathrm{~A} \mathrm{~cm}{ }^{-2}$ for 4,4', $4^{\prime \prime}$-tris(N-3-methylphenyl-N- phenyl-amino)-triphenylamine [32], poly(2,6-diphenyl-4-((9-ethyl)-9H-carbazole)-pyridinyl-alt-2,7-(9,9-didodecyl)-9H-fluorenyl) [50], and $\mathrm{N}, \mathrm{N}^{\prime}$-bis(3-methylphenyl)-N, $\mathrm{N}^{\prime}$-diphenylbenzidine [51], and even higher ohmic current densities 
were also found with a few of carbazole derivatives [52]. In addition, a few photoluminescent devices were successfully demonstrated using EHCz as a host material in the previous studies $[5,6,8]$; however, at the current stage, we could not observe electroluminescence from dye-doped $\mathrm{EHCz}$ materials due to the imbalance of electrons and holes.
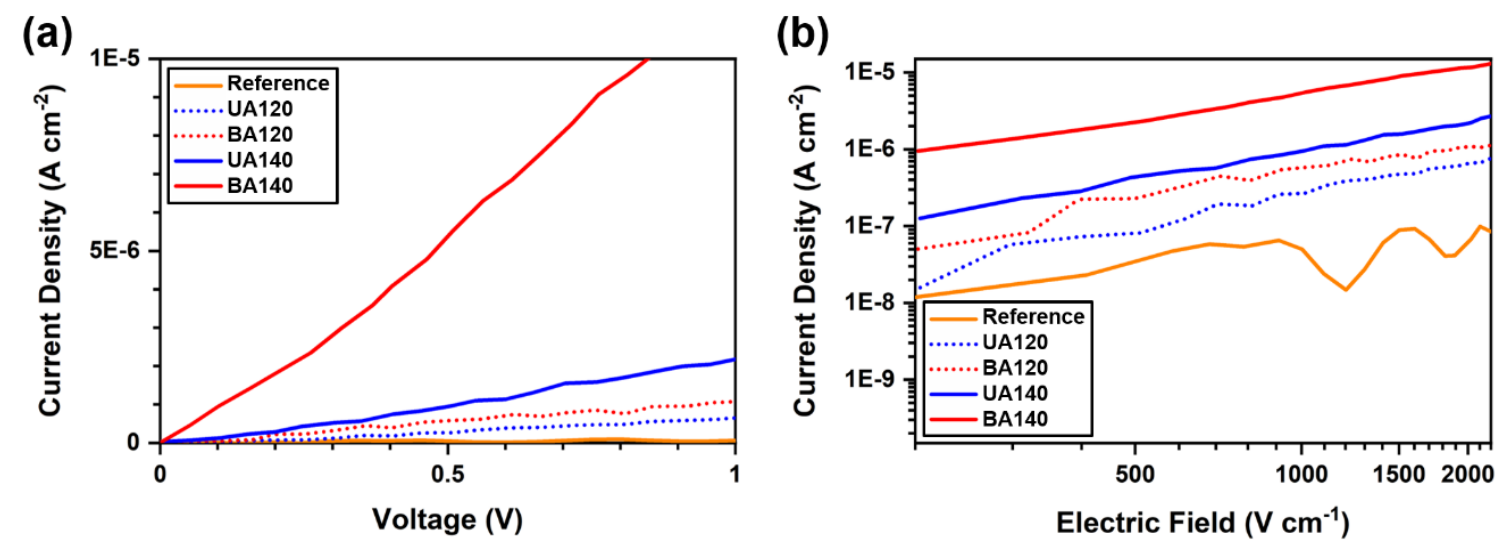

Figure 5. (a) Current density-voltage (J-V) characteristics of the devices using the reference, UA120, UA140, BA120, and BA140 electrodes, in a linear scale. The characteristics were measured in low bias region (i.e., ohmic current region). All the characteristics showed a linear relationship, and that the slope ratio of the device with the BA140 electrode to the reference devices was $\sim 170$. (b) Electric field dependence of the current density. All the slopes were measured to be $\sim 1$, indicating ohmic current in each device.

The field intensity calculation was also performed to investigate the local electric field enhancement induced by a highly cracked metal structure as shown in Figure 6. The cracked Ag structure with a depth of $30 \mathrm{~nm}$ was considered for the calculation, on the basis of the observed SEM image (see Figure $6 \mathrm{~b}$ ). In the simulation model, the gap distance between the lower Ag and upper ITO electrodes was fixed at $5 \mu \mathrm{m}$, and the gap was filled with a dielectric material corresponding to EHCz. For the dielectric material, dielectric constant of 3.02, electrical conductivity of $2.1 \times 10^{-9} \mathrm{~S} \mathrm{~cm}^{-1}$, and density of $1.004 \mathrm{~g} \mathrm{~mL}^{-1}$ were used as material parameters to simulate EHCz. It should be noted that the dielectric constant of $\mathrm{EHCz}$ was experimentally measured for this work. For the measurement, EHCz was injected into the gap between two Ag electrodes with a gap distance of $5 \mu \mathrm{m}$, of which the capacitance was monitored at a frequency of $1 \mathrm{kHz}$. The measured capacitance was converted into the dielectric constant in consideration of active area and thickness.

Static analysis was performed to clarify the spatial distribution of local electric fields within the device at a fixed bias voltage of $+1.0 \mathrm{~V}$. According to the distance from the Ag bottom, the local electric field intensities were calculated for the selected cross sections, as shown in Figure 6a. The local electric field intensities were significantly enhanced within the cracks of the Ag electrode, of which apexes were found at the upper edges. In particular, the intensity of the local electric field increased up to $\sim 4000 \mathrm{~V}$ $\mathrm{cm}^{-1}$ at the upper edges. To clearly show the local electric field enhancement, the field intensities for the selected cross section were further visualized as shown in Figure 6c. These calculation results were in good agreement with the experimental results, where charge injection properties were dramatically improved by the high-density cracks contributing to local electric field enhancement. 
(a)

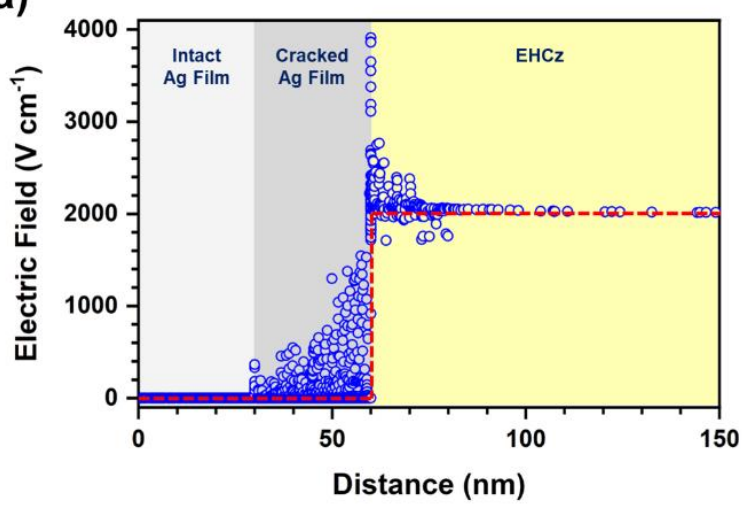

(b)
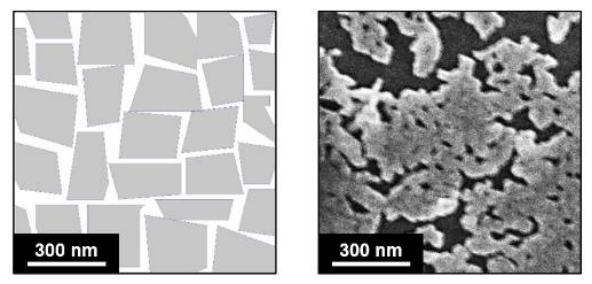

(c)

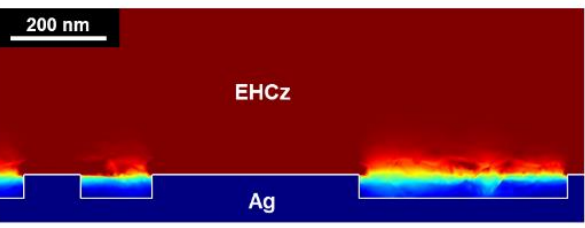

Figure 6. (a) Local electric field intensities according to the distance from the Ag bottom, based on the field intensity calculation at a fixed bias voltage of $+1.0 \mathrm{~V}$. Blue circles indicate the local electric field intensities in the device with a highly cracked Ag structure (30-nm depth), and a red dashed line indicates the electric field in the reference device. (b) Model structure configured for the field intensity calculation in (a), and SEM image of BA140 used to prepare the model structure. (c) Local electric field intensities visualized for a selected cross section. The boundary between Ag and EHCz is indicated by a white line. The intensity level, presented by colors, increases from blue to red (i.e., blue-green-yellow-red).

\section{Summary}

We demonstrate efficient charge injection into solvent-free liquid organic semiconductors via cracked metal structures with a large number of edges leading to local electric field enhancement. For this work, the Ag thin films on the deformable FEP substrates were mechanically stretched to generate the cracks on the surfaces in a controlled manner, and subsequently transferred and welded onto other intact $\mathrm{Ag}$ films for avoiding increases in electrical resistance. Using the prepared $\mathrm{Ag}$ electrodes with varied crack densities, the charge injection properties into $\mathrm{EHCz}$ were investigated in low bias region (i.e., ohmic current region). It was found that the device with the highly cracked electrode dramatically increased the current density within the ohmic current region, indicating that efficient charge injection via local electric field enhancement can exert similar effects to the introduction of ionic dopants on J-V characteristics in terms of charge carrier concentrations. Although the hole-only devices were demonstrated in this work, these results still offer a wide range of possibilities for various device applications. Careful consideration of work functions of electrodes and cascade energy levels would be required for optimizing the device design or selection of device components. In addition, the field intensity within the device was calculated using COMSOL Multiphysics software, based on the experimental observation, and static analysis was also performed to reveal the spatial distribution of local electric fields. The calculation results were in good agreement with our experimental results, where charge injection properties were dramatically improved by the high-density cracks contributing to local electric field enhancement. We anticipated that these results will significantly contribute to the development and further refinement of various organic electronic and optoelectronic devices based on non-volatile liquid organic semiconducting materials.

Author Contributions: K.-H.K.: methodology, software, formal analysis, investigation, data curation, visualization, and writing-original draft preparation; M.-J.P.: methodology, software, resources, and supervision; J.-H.K.: conceptualization, methodology, validation, writing - original draft preparation, review and editing, supervision, project administration, funding acquisition. All authors have read and agreed to the published version of the manuscript.

Funding: This research was funded by the Basic Science Research Program through the National Research Foundation of Korea (NRF-2018R1C1B6003122).

Conflicts of Interest: The authors declare no conflict of interest. 


\section{References}

1. Ribierre, J.-C.; Aoyama, T.; Muto, T.; Imase, Y.; Wada, T. Charge transport properties in liquid carbazole. Org. Electron. 2008, 9, 396-400. [CrossRef]

2. Schmidt, H.; Hawkins, A.R. The photonic integration of non-solid media using optofluidics. Nat. Photon. 2011, 5, 598-604. [CrossRef]

3. Kamino, B.A.; Bender, T.P.; Klenkler, R.A. Hole mobility of a liquid organic semiconductor. J. Phys. Chem. Lett. 2012, 3, 1002-1006. [CrossRef]

4. Babu, S.S.; Aimi, J.; Ozawa, H.; Shirahata, N.; Saeki, A.; Seki, S.; Ajayaghosh, A.; Möhwald, H.; Nakanishi, T. Solvent-free luminescent organic liquids. Angew. Chem. Int. Ed. Engl. 2012, 51, 3391-3395. [CrossRef]

5. Choi, E.Y.; Mager, L.; Cham, T.T.; Dorkenoo, K.D.; Fort, A.; Wu, J.W.; Barsella, A.; Ribierre, J.-C. Solvent-free fluidic organic dye lasers. Opt. Express 2013, 21, 11368-11375. [CrossRef]

6. Kim, J.-H.; Inoue, M.; Zhao, L.; Komino, T.; Seo, S.; Ribierre, J.-C.; Adachi, C. Tunable and flexible solvent-free liquid organic distributed feedback lasers. Appl. Phys. Lett. 2015, 106, 053302. [CrossRef]

7. Ribierre, J.C.; Zhao, L.; Inoue, M.; Schwartz, P.O.; Kim, J.H.; Yoshida, K.; Sandanayaka, A.S.; Nakanotani, H.; Mager, L.; Mery, S.; et al. Low threshold amplified spontaneous emission and ambipolar charge transport in non-volatile liquid fluorene derivatives. Chem. Commun. 2016, 52, 3103-3106. [CrossRef] [PubMed]

8. Sandanayaka, A.S.D.; Zhao, L.; Pitrat, D.; Mulatier, J.-C.; Matsushima, T.; Andraud, C.; Kim, J.-H.; Ribierre, J.-C.; Adachi, C. Improvement of the quasi-continuous-wave lasing properties in organic semiconductor lasers using oxygen as triplet quencher. Appl. Phys. Lett. 2016, 108, 223301. [CrossRef]

9. Snaith, H.J.; Zakeeruddin, S.M.; Wang, Q.; Péchy, P.; Grätzel, M. Dye-sensitized solar cells incorporating a liquid hole-transporting material. Nano Lett. 2006, 6, 2000-2003. [CrossRef]

10. Ribierre, J.-C.; Aoyama, T.; Kobayashi, T.; Sassa, T.; Muto, T.; Wada, T. Influence of the liquid carbazole concentration on charge trapping in $\mathrm{C}_{60}$ sensitized photorefractive polymers. J. Appl. Phys. 2007, 102, 033106. [CrossRef]

11. Xu, D.; Adachi, C. Organic light-emitting diode with liquid emitting layer. Appl. Phys. Lett. 2009, 95, 053304. [CrossRef]

12. Ribierre, J.-C.; Aoyama, T.; Muto, T.; André, P. Hybrid organic-inorganic liquid bistable memory devices. Org. Electron. 2011, 12, 1800-1805. [CrossRef]

13. Hirata, S.; Kubota, K.; Jung, H.H.; Hirata, O.; Goushi, K.; Yahiro, M.; Adachi, C. Improvement of electroluminescence performance of organic light-emitting diodes with a liquid-emitting layer by introduction of electrolyte and a hole-blocking layer. Adv. Mater. 2011, 23, 889-893. [CrossRef]

14. Kubota, K.; Hirata, S.; Shibano, Y.; Hirata, O.; Yahiro, M.; Adachi, C. Liquid carbazole substituted with a poly(ethylene oxide) group and its application for liquid organic light-emitting diodes. Chem. Lett. 2012, 41, 934-936. [CrossRef]

15. Shim, C.-H.; Hirata, S.; Oshima, J.; Edura, T.; Hattori, R.; Adachi, C. Uniform and refreshable liquid electroluminescent device with a back side reservoir. Appl. Phys. Lett. 2012, 101, 113302. [CrossRef]

16. Kasahara, T.; Matsunami, S.; Edura, T.; Oshima, J.; Adachi, C.; Shoji, S.; Mizuno, J. Fabrication and performance evaluation of microfluidic organic light emitting diode. Sensor. Actuat. A Phys. 2013, 195, 219-223. [CrossRef]

17. Plint, T.G.; Kamino, B.A.; Bender, T.P. Charge carrier mobility of siliconized liquid triarylamine organic semiconductors by time-of-flight spectroscopy. J. Phys. Chem. C 2015, 4, 1676-1682. [CrossRef]

18. Coropceanu, V.; Cornil, J.; da Silva Filho, D.A.; Olivier, Y.; Silbey, R.; Brédas, J.-L. Charge transport in organic semiconductors. Chem. Rev. 2007, 107, 926-952. [CrossRef]

19. Forrest, S.R. Ultrathin organic films grown by organic molecular beam deposition and related techniques. Chem. Rev. 1997, 97, 1793-1896. [CrossRef]

20. Ishii, H.; Sugiyama, K.; Ito, E.; Seki, K. Energy level alignment and interfacial electronic structures at organic/metal and organic/organic interfaces. Adv. Mater. 1999, 11, 605-625. [CrossRef]

21. Hooks, D.E.; Fritz, T.; Ward, M.D. Epitaxy and molecular organization on solid substrates. Adv. Mater. 2001, 13, 227-241. [CrossRef]

22. Zhu, X.-Y. Electronic structure and electron dynamics at molecule-metal interfaces: Implications for molecule-based electronics. Surf. Sci. Rep. 2004, 56, 1-83. [CrossRef] 
23. Yamane, H.; Kanai, K.; Ouchi, Y.; Ueno, N.; Seki, K. Impact of interface geometric structure on organic-metal interface energetics and subsequent films electronic structure. J. Electron Spectrosc. Relat. Phenom. 2009, 174, 28-34. [CrossRef]

24. Ma, H.; Yip, H.-L.; Huang, F.; Jen, A.K.-Y. Interface engineering for organic electronics. Adv. Funct. Mater. 2010, 20, 1371-1388. [CrossRef]

25. Kim, J.-H. Interfacial phenomena between conjugated organic molecules and noble metals. Korean J. Chem. Eng. 2017, 34, 1281-1293. [CrossRef]

26. Jain, S.; Geens, W.; Mehra, A.; Kumar, V.; Aernouts, T.; Poortmans, J.; Mertens, R.; Willander, M. Injection-and space charge limited-currents in doped conducting organic materials. J. Appl. Phys. 2001, 89, 3804-3810. [CrossRef]

27. Hosseini, A.; Wong, M.H.; Shen, Y.; Malliaras, G.G. Charge injection in doped organic semiconductors. J. Appl. Phys. 2005, 97, 023705. [CrossRef]

28. Matsushima, T.; Kinoshita, Y.; Murata, H. Formation of ohmic hole injection by inserting an ultrathin layer of molybdenum trioxide between indium tin oxide and organic hole-transporting layers. Appl. Phys. Lett. 2007, 91, 253504. [CrossRef]

29. Kim, J.; Khang, D.-Y.; Kim, J.-H.; Lee, H.H. The surface engineering of top electrode in inverted polymer bulk-heterojunction solar cells. Appl. Phys. Lett. 2008, 92, 133307. [CrossRef]

30. Kim, J.-H.; Huh, S.-Y.; Kim, T.-i.; Lee, H.H. Thin pentacene interlayer for polymer bulk-heterojunction solar cell. Appl. Phys. Lett. 2008, 93, 143305. [CrossRef]

31. Lee, J.-H.; Leem, D.-S.; Kim, H.-J.; Kim, J.-J. Effectiveness of p-dopants in an organic hole transporting material. Appl. Phys. Lett. 2009, 94, 123306. [CrossRef]

32. Shan, M.; Jiang, H.; Guan, Y.; Sun, D.; Wang, Y.; Hua, J.; Wang, J. Enhanced hole injection in organic light-emitting diodes utilizing a copper iodide-doped hole injection layer. RSC Adv. 2017, 7, 13584-13589. [CrossRef]

33. Arkhipov, V.; Emelianova, E.; Tak, Y.; Bässler, H. Charge injection into light-emitting diodes: Theory and experiment. J. Appl. Phys. 1998, 84, 848-856. [CrossRef]

34. Mahapatro, A.K.; Ghosh, S. Schottky energy barrier and charge injection in metal/copper-phthalocyanine/metal structures. Appl. Phys. Lett. 2002, 80, 4840-4842. [CrossRef]

35. Fowler, R.H.; Nordheim, L. Electron emission in intense electric fields. Proc. R. Soc. A 1928, 119, $173-181$.

36. De Heer, W.A.; Chatelain, A.; Ugarte, D. A carbon nanotube field-emission electron source. Science 1995, 270, 1179-1180. [CrossRef]

37. Fujii, S.; Honda, S.-i.; Machida, H.; Kawai, H.; Ishida, K.; Katayama, M.; Furuta, H.; Hirao, T.; Oura, K. Efficient field emission from an individual aligned carbon nanotube bundle enhanced by edge effect. Appl. Phys. Lett. 2007, 90, 153108. [CrossRef]

38. Li, Y.; Sun, Y.; Yeow, J.T. Nanotube field electron emission: Principles, development, and applications. Nanotechnology 2015, 26, 242001. [CrossRef]

39. Ye, T.; Suo, Z.; Evans, A. Thin film cracking and the roles of substrate and interface. Int. J. Solids Struct. 1992, 29, 2639-2648. [CrossRef]

40. Li, T.; Suo, Z. Deformability of thin metal films on elastomer substrates. Int. J. Solids Struct. 2006, 43, 2351-2363. [CrossRef]

41. Kang, D.; Pikhitsa, P.V.; Choi, Y.W.; Lee, C.; Shin, S.S.; Piao, L.; Park, B.; Suh, K.-Y.; Kim, T.-i.; Choi, M. Ultrasensitive mechanical crack-based sensor inspired by the spider sensory system. Nature 2014, 516, 222-226. [CrossRef] [PubMed]

42. Park, B.; Kim, J.; Kang, D.; Jeong, C.; Kim, K.S.; Kim, J.U.; Yoo, P.J.; Kim, T.-i. Dramatically enhanced mechanosensitivity and signal-to-noise ratio of nanoscale crack-based sensors: Effect of crack depth. Adv. Mat. 2016, 28, 8130-8137. [CrossRef] [PubMed]

43. Kim, M.; Choi, H.; Kim, T.; Hong, I.; Roh, Y.; Park, J.; Seo, S.; Han, S.; Koh, J.-s.; Kang, D. FEP encapsulated crack-based sensor for measurement in moisture-laden environment. Materials 2019, 12, 1516. [CrossRef] [PubMed]

44. Bay, N. Cold pressure welding-The mechanisms governing bonding. J. Eng. Ind. 1979, 101, 121-127. [CrossRef]

45. Kim, C.; Burrows, P.E.; Forrest, S.R. Micropatterning of organic electronic devices by cold-welding. Science 2000, 288, 831-833. [CrossRef] 
46. Kim, C.; Shtein, M.; Forrest, S.R. Nanolithography based on patterned metal transfer and its application to organic electronic devices. Appl. Phys. Lett. 2002, 80, 4051-4053. [CrossRef]

47. Asare, J.; Adeniji, S.; Oyewole, O.; Agyei-Tuffour, B.; Du, J.; Arthur, E.; Fashina, A.; Zebaze Kana, M.; Soboyejo, W. Cold welding of organic light emitting diode: Interfacial and contact models. AIP Adv. 2016, 6, 065125. [CrossRef]

48. Varo, P.L.; Tejada, J.J.; Villanueva, J.L.; Carceller, J.; Deen, M. Modeling the transition from ohmic to space charge limited current in organic semiconductors. Org. Electron. 2012, 13, 1700-1709. [CrossRef]

49. Wetzelaer, G.; Blom, P.W. Ohmic current in organic metal-insulator-metal diodes revisited. Phys. Rev. B 2014, 89, 241201. [CrossRef]

50. Liu, B.G.; Liaw, D.-J.; Lee, W.-Y.; Ling, Q.-D.; Zhu, C.-X.; Chan, D.S.-H.; Kang, E.-T.; Neoh, K.-G. Tristable electrical conductivity switching in a polyfluorene-diphenylpyridine copolymer with pendant carbazole groups. Phil. Trans. R. Soc. A 2009, 367, 4203-4214. [CrossRef]

51. Havare, A.K. Effect of the interface improved by self-assembled aromatic organic semiconductor molecules on performance of OLED. ECS J. Solid State Sci. Technol. 2020, 9, 041007. [CrossRef]

52. Noine, K.; Pu, Y.-J.; Nakayama, K.-i.; Kido, J. Bifluorene compounds containing carbazole and/or diphenylamine groups and their bipolar charge transport properties in organic light emitting devices. Org. Electron. 2010, 11, 717-723. [CrossRef]

(C) 2020 by the authors. Licensee MDPI, Basel, Switzerland. This article is an open access article distributed under the terms and conditions of the Creative Commons Attribution (CC BY) license (http://creativecommons.org/licenses/by/4.0/). 